
\title{
25 Research Soure \\ The Ability of Shock Index In Detecting Postpartum Haemorrhage: A Retrospective Case-Control Study
}

\section{Liqiong Huang}

University of Electronic Science and Technology of China

Xiaoqin Gan

University of Electronic Science and Technology of China

Dan Luo

University of Electronic Science and Technology of China

Jiajia Zhang

University of Electronic Science and Technology of China

\section{Mengjun Wu}

University of Electronic Science and Technology of China

Zheng'ai Xiong ( $\mathbf{3}$ 300534@hospital.cqmu.edu.cn )

The Second Affiliated Hospital of Chongqing Medical University

\section{Research Article}

Keywords: postpartum haemorrhage, shock index, blood transfusion, surgical intervention, systolic blood pressure, heart rate.

Posted Date: January 27th, 2022

DOI: https://doi.org/10.21203/rs.3.rs-1255336/v1

License: (c) (i) This work is licensed under a Creative Commons Attribution 4.0 International License.

Read Full License 


\section{Abstract}

Background: shock index (SI), calculated as the ratio of heart rate (HR) to systolic blood pressure (SBP), is used to measure the degree of hypovolemia in shock states. Little literature reported on the role of SI in detecting postpartum haemorrhage (PPH) in obstetrics. This study aimed to determine whether SI was superior to clinical criteria to identify PPH, to identify independent risk factors of surgical intervention and blood transfusion.

Materials and Methods: Records were retrospectively examined for patients who experienced PPH $(n=305)$ or not $(n=305)$. HR and SBP were recorded at five different time points from admission to postpartum $24 \mathrm{~h}$. The performance of vital signs based on area under the receiver operating characteristic curve (AUROC) was used to evaluate the ability among peak SI, HR, SBP for estimating $\mathrm{PPH}$. Two formulas using the fitted curve in a scatter plot (maximum SI and blood loss postpartum $24 \mathrm{~h}$ based on draps weighing method against blood loss postpartum $24 \mathrm{~h}$ with hemoglobinometry, respectively) were provided to determine the ability between SI and draps weighing method in detecting $\mathrm{PPH}$. Univariate and logistic regression analyses were used to determine predictors of surgical intervention and blood transfusion. The sensitivity and specificity of SI for predicting transfusion were calculated.

Results: SI had the highest AUROC of 0.646 [95\% confidence interval $(\mathrm{Cl}), 0.590-0.700]$ and $0.665(95 \% \mathrm{Cl}$, 0.582-0.748) for PPH of $\geq 1,000$ and $\geq 1,500 \mathrm{ml}$. SI was inferior to drapes weighing method (coefficient of correlation, 0.351 vs 0.759 ) in estimating PPH. Caesarean delivery, placenta previa were independent risk factors for surgical interventions and transfusion. Body mass index(BMI) and peak $\mathrm{SI} \geq 1$ were also independent risk factors for transfusion. The $\mathrm{SI} \geq 1$ predicted transfusion with a specificity of 0.81 , negative predictive value $82 \%$ but sensitivity of only 0.39 .

Conclusions: The peak SI may be superior to HR or SBP for detecting PPH. However, due to the low correlation with blood loss, the severity of PPH needs to be judged accompanied with other signs and symptoms. SI 1 may indicate no blood transfusion needed.

\section{Background}

Postpartum haemorrhage (PPH) is one of the top five causes of maternal mortality in both developed and developing countries [1]. American College of Obstetricians and Gynaecologists (ACOG) defines PPH as cumulative blood loss no less than $1,000 \mathrm{ml}$ or blood loss accompanied by signs or symptoms of hypovolemia within 24 hours after the birth process (includes intrapartum loss) [2]. However, despite this new characterization, a blood loss greater than $500 \mathrm{ml}$ in a vaginal delivery should be considered abnormal and should pay attention to reason analysis and problem solutions. In the study, we still defined PPH as an estimated blood loss no less than $500 \mathrm{ml}$ for vaginal deliveries and no less than 1000 $\mathrm{ml}$ for caesarean deliveries within 24 hours after delivery, and defined severe PPH as more than 4 red cell packs transfused [3]. Recent estimates suggested that $29.3 \%$ of maternal deaths and $26.7 \%$ of severe 
adverse maternal outcomes globally were due to PPH [4-6]. Severe maternal outcomes following PPH suggested the need to improve quality of timely recognition and treatment during and after delivery [7].

Inaccurate estimation of postpartum bleeding delayed the timely intervention of $\mathrm{PPH}$, which can lead to worse outcomes [8]. Because of the compensatory mechanism, heart rate (HR) or systolic blood pressure (SBP) changed inconsistently at different stages of shock. However, shock index (SI), calculated as the ratio of HR to SBP, increased with the increasing amount of blood loss. Therefore, HR or SBP alone may not reliably predict whether ruptured ectopic pregnant women were at risk of $\mathrm{PPH}, \mathrm{SI}$ was superior to HR or SBP alone for assessing the ratio of blood loss to total blood volume in ruptured ectopic pregnant women [9-11]. Despite this promising research with SI, little literature reported the usefulness of SI in detecting PPH, transfusion and surgical intervention.

In the present work, we aimed (1) to determine whether SI was superior to HR or SBP in predicting PPH; (2) to determine whether SI was superior to drapes weighing method in estimating PPH; (3) to identify independent risk factors of transfusion and surgical intervention.

\section{Materials And Methods}

The study was conducted retrospectively. $305 \mathrm{PPH}$ and 305 patients without PPH who had normal vaginal or caesarean deliveries without adverse outcomes included as a control group were recruited through our hospital from June 2018 to December 2018. The requirement for written informed consent was waived because of the retrospective nature of the study.

Women with PPH were included if they experienced blood loss no less than $500 \mathrm{ml}$ (vaginal deliveries) or $1000 \mathrm{ml}$ (caesarean deliveries) within $24 \mathrm{~h}$ after delivery. During this period, blood loss was recorded based on drapes weighing method without amniotic fluid from delivery of the placenta to postpartum 24 h. We excluded women with massive haemorrhage $(>5 \mathrm{~L})$ or hemoglobin $(\mathrm{Hb})<70 \mathrm{~g} / \mathrm{L}$ since most such cases were due to placenta previa or placenta accreta, proactively given transfusions which may change SI. We also excluded women with gestational hypertension, hyperthyroidism, hypothyroidism, sinus tachycardia or sinus bradycardia, which can alter HR and SBP.

We retrospectively collected the demographic and clinical characteristics, postpartum outcomes, laboratory indexes including age, weight before delivery, body mass index (BMI) before delivery, parity, complications, gestational age at delivery, mode of delivery, surgical interventions, blood transfusion or not, hemoglobin before delivery and 24 hours after delivery. HR, SBP were recorded at admission, following delivery of the placenta, postpartum $1 \mathrm{~h}$, and postpartum $2 \mathrm{~h}$ and when large amount of bleeding appeared in 24 hours after delivery. Peak SI was defined as the highest value among four time points (following delivery of the placenta, postpartum $1 \mathrm{~h}$, and postpartum $2 \mathrm{~h}$, when large amount of bleeding appeared).

When PPH occurred, we should find the cause and resolved it with etiological treatment. Administration of prophylactic uterotonics (oxytocin) before delivery of the placenta and controlled cord traction could 
effectively prevent PPH at the third stage of labor [12]. Treatment for PPH include the use of additional uterotonics (prostaglandins or ergometrine ), uterine massage, and fluid resuscitation with isotonic crystalloids, tranexamic acid use, blood transfusion and surgical interventions. Surgical interventions include intrauterine balloon or gauze tamponade, B-Lynch suture technique, pelvic vessel ligation, uterine artery embolization and hysterectomy. Laceration suture or hematoma removal should be performed when laceration of the cervix or vagina occurred. Postoperative adjuvant mifepristone or MTX was required when placental accreta occurred $[13,14]$.

In order to estimate the relationship between SI and corresponding blood loss, we calculated the average value of peak SI at the following stages of postpartum hemorrhage group and control group: less than $500 \mathrm{ml}, 500-1000 \mathrm{ml}, 1000-1500 \mathrm{ml}, 1500-2000 \mathrm{ml},>2000 \mathrm{ml}$.

In order to determine whether SI was superior to drapes weighing method in estimating PPH, one formula for the total blood loss using the fitted curve in a scatter plot (maximum SI and total blood loss postpartum $24 \mathrm{~h}$ with hemoglobinometry) and another formula (blood loss postpartum $24 \mathrm{~h}$ based on draps weighing method and blood loss postpartum $24 \mathrm{~h}$ with hemoglobinometry) including both PPH group and control group were provided. For every $10 \mathrm{~g} / \mathrm{L}$ decrease in $\mathrm{Hb}$, the corresponding blood loss was $400 \mathrm{ml}$. The volume of blood loss in PPH 24 hours after delivery was calculated according to the formula: blood loss $(\mathrm{ml})=(\mathrm{Hb}$ before delivery $-24 \mathrm{~h}$ after delivery $) / 10 * 400$ [15]. This was considered as the reference value for assessing the accuracy of PPH at 24 hours after delivery based on peak SI or based on conventional clinical indicators (drapes weighing method).

To determine whether $\mathrm{SI}$ is better at detecting PPH than other vital signs such as HR or SBP, we evaluated the performance of vital signs based on AUROC when postpartum blood loss was $>1000 \mathrm{ml}$ or $1500 \mathrm{ml}$.

In order to find the causes of surgical interventions and transfusion, we regarded BMI, age and the indicators with statistically significant differences in Table 1 as independent variables, regarded surgical interventions and transfusion as dependent variables. Then we did univariate and logistic regression analyses. Sensitivity, specificity, positive likelihood ratio and negative likelihood ratio were calculated for prediction of blood transfusion.

Statistical analysis was performed using SPSS 20.0 (IBM, Armonk, NY, USA). Student's t test was used to compare continuous variables showing a normal distribution, while the Mann-Whitney $\mathrm{U}$ test was used for data showing a skewed distribution. Chi-squared and Fisher's exact tests were used to compare categorical data. Differences associated with $P<0.05$ were considered statistically significant.

\section{Results}

A total of 9170 pregnant women who gave birth were identified in the database, of whom 305 experienced PPH and nobody died in hospital. Among women with PPH, 125 gave birth by caesarean section, 163 were through spontaneous vaginal delivery and 17 were through forceps-assisted vaginal delivery. Among women who suffered PPH, 5 underwent hysterectomy and 13 received uterine artery 
embolization. Women who underwent hysterectomy were all caesarean-scarred uterus with placenta accreta. Of 13 women who underwent uterine artery embolization, 8 had cesarean-scarred uterus with placenta accreta, 2 had twins, 1 had uterine atony of lower uterine segment after vaginal delivery, 1 had breech birth, 1 had severe preeclampsia. Among women with PPH, 30 had fetal macrosomia, 25 had twins, 95 had placental accreta, 66 had placenta previa, 6 had placental abruption, 6 had low-lying placenta, 13 had chorioamnionitis, 34 had breech birth, 16 had intrahepatic cholestasis of pregnancy and 14 had no complications.

Among $305 \mathrm{PPH}, 69$ received blood transfusion with 24 received more than 4 red cell packs and 45 received no more than 4 red cell packs. Among 24 with severe PPH, 11 had caesarean-scarred uterus with placenta accreta, 7 had total placenta previa, 1 had uterine atony of lower uterine segment after vaginal delivery, 3 had hepatitis B virus, 2 had placenta accreta. Patients in PPH group had a higher incidence of complications than those in the control group, including fetal macrosomia, twins, placenta accreta, placenta previa, caesarean-scarred uterus, placental abruption, chorioamnionitis, and intrahepatic cholestasis of pregnancy. The following values were higher in PPH group than in control group: parity, spontaneous vaginal delivery, forceps-assisted vaginal delivery, the amount of postpartum bleeding, peak SI, peak SI in vaginal delivery, peak SI in cesarean delivery, SBP at admission, HR of peak SI. The following values were lower in PPH group than in control group: gestational age at delivery, cesarean delivery, $\mathrm{Hb}$ before delivery, $\mathrm{Hb} 24$ hours later after delivery. No significant differences were found in the following values between the PPH and control groups: mean maternal age, weight before delivery, body mass index before delivery, SI at admission, HR at admission, SBP of peak SI (Table 1).

Table1. Demographic and clinical characteristics, postpartum outcomes, laboratory indexes of patients who experienced PPH or not. 


\begin{tabular}{|c|c|c|c|}
\hline & $\begin{array}{l}\text { PPH group } \\
(n=305)\end{array}$ & $\begin{array}{l}\text { Control group } \\
(n=305)\end{array}$ & $P$ \\
\hline Mean maternal age $\varangle$ years $\rrbracket$ & $29.8 \pm 4.2$ & $29.8 \pm 3.8$ & 0.984 \\
\hline Weight before delivery $₫ \mathrm{Kg} \rrbracket$ & $67.9 \pm 8.4$ & $66.6 \pm 8.6$ & 0.051 \\
\hline Body mass index before delivery $\varangle \mathrm{kg} / \mathrm{m}^{2} \square$ & $26.5 \pm 2.8$ & $26.5 \pm 6.6$ & 0.987 \\
\hline \multicolumn{4}{|l|}{ Parity $(n, \%)$} \\
\hline P1 & $178(58)$ & 203(67) & 0.037 \\
\hline$\geq \mathrm{P} 2$ & $127(42)$ & 102(33) & \\
\hline Gestational age at delivery $\llbracket$ week $\rrbracket$ & $38.2 \pm 2.4$ & $39.0 \pm 1.3$ & 0.000 \\
\hline \multicolumn{4}{|l|}{ Mode of delivery $(n, \%)$} \\
\hline Spontaneous vaginal delivery & 163(53) & $110(36)$ & 0.000 \\
\hline Forceps-assisted vaginal delivery & $17(6)$ & $0(0)$ & \\
\hline Cesarean delivery & $125(41)$ & 195(64) & \\
\hline The amount of postpartum bleeding & $1116.5 \pm 654.9$ & $429.9 \pm 126.0$ & 0.000 \\
\hline $\mathrm{Hb}$ before delivery $\llbracket \mathrm{g} / \mathrm{L} \rrbracket$ & $117.8 \pm 13.9$ & $120.7 \pm 13.1$ & 0.009 \\
\hline $\mathrm{Hb} 24$ hours later after delivery $₫ \mathrm{~g} / \mathrm{L} \rrbracket$ & $89.8 \pm 15.6$ & $110.3 \pm 14.3$ & 0.000 \\
\hline Peak SI & $0.9 \pm 0.2$ & $0.8 \pm 0.1$ & 0.000 \\
\hline Peak SI in vaginal delivery & $0.9 \pm 0.2$ & $0.8 \pm 0.1$ & 0.000 \\
\hline Peak SI in cesarean delivery & $0.9 \pm 0.1$ & $0.8 \pm 0.1$ & 0.000 \\
\hline $\mathrm{HR}$ at admission & $84.7 \pm 7.2$ & $84.4 \pm 9.0$ & 0.620 \\
\hline SBP at admission & $114.6 \pm 9.3$ & $112.6 \pm 9.2$ & 0.007 \\
\hline SI at admission(HR/SBP at admission $\rrbracket$ & $0.7 \pm 0.1$ & $0.8 \pm 0.1$ & 0.254 \\
\hline HR of peak SI & $95.4 \pm 14.5$ & $84.6 \pm 7.9$ & 0.000 \\
\hline SBP of peak SI & $106.2 \pm 9.2$ & $107.3 \pm 8.1$ & 0.137 \\
\hline
\end{tabular}

PPH: postpartum hemorrhage, SI: shock index, HR: heart rate, SBP: systolic blood pressure. Hb: hemoglobin. Values shown are mean $\pm S D, n(\%)$.

Table 2 described SI values corresponding to postpartum blood loss at each stage between PPH group and control group: the average SI values of blood loss were $0.80,0.87,0.92,0.95$ and 1.06 , respectively, corresponding to blood loss in $₫ 500 \mathrm{ml}$ in control group and $500-1000 \mathrm{~mL}, 1000-1500 \mathrm{ml}$ and $>2000 \mathrm{ml}$ in 
PPH group. The SI value corresponding to $500-1000 \mathrm{ml}$ blood loss in the control group was 0.75 , which referred to patients with $500-1000 \mathrm{ml}$ blood loss after caesarean section.

Table 2

SI distribution corresponding to postpartum bleeding at different stage in PPH group and control group

\begin{tabular}{|lll|}
\hline PPH & PPH group $(\overline{\boldsymbol{x}})$ & Control group $(\overline{\boldsymbol{x}})$ \\
\hline$<500 \mathrm{ml}$ & & $0.80(0.65 \sim 1.07)$ \\
\hline$[500,1000) \mathrm{ml}$ & $0.87(0.68 \sim 1.18)$ & $0.75(0.62 \sim 0.87)$ \\
\hline$[1000,1500) \mathrm{ml}$ & $0.92(0.62 \sim 1.49)$ & \\
\hline$[1500,2000) \mathrm{ml}$ & $0.95(0.72 \sim 1.49)$ & \\
\hline$>2000 \mathrm{ml}$ & $1.06(0.78 \sim 1.68)$ & \\
\hline PPH: postpartum hemorrhage & \\
\hline
\end{tabular}

SI was inferior to clinical estimation of postpartum bleeding based on drapes weighing method in detecting PPH (coefficient of correlation, 0.351 vs 0.759 ) (Figure a and figure b). Figure a showed a fitted curve with the maximum SI plotted against total blood loss calculated by hemoglobinometry for the PPH group and control group, depicting the distribution. The coefficient of determination (R2) was 0.1239 and the coefficient of correlation was 0.351 , indicating a low correlation between maximum $\mathrm{SI}$ and blood loss.

To determine whether SI is better at detecting PPH than other vital signs including HR and SBP, we evaluated the performance of vital signs based on AUROC. Table 3 summarized the AUROC values with

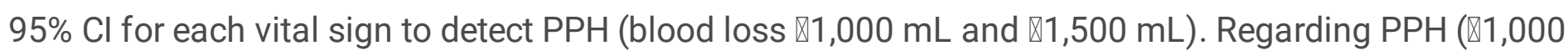
and $\otimes 1,500 \mathrm{~mL})$, SI had the highest AUROC of 0.646 (0.590-0.700) and 0.665 (0.582-0.748), respectively. SI was significantly higher than the AUROC of HR ( $<<0.0001$ and $p=0.0001$, respectively) and SBP $(p<0.05$

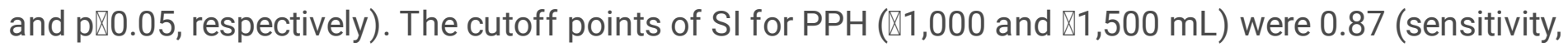
$61.88 \%$; specificity, $66.21 \%$ ) and 0.87 (sensitivity, $75.6 \%$; specificity, $56.2 \%$ ), respectively. The cutoff points of HR for PPH ( $₫ 1,000$ and $₫ 1,500 \mathrm{~mL}$ ) were $91 \mathrm{bpm}$ (sensitivity, $57.5 \%$; specificity, $61.4 \%$ ) and $90 \mathrm{bpm}$ (sensitivity, 62.2\%; specificity, $52.3 \%$ ), respectively. 
Table 3

AUROC values with $95 \%$ confidence interval of vital signs to detect postpartum hemorrhage

\begin{tabular}{|c|c|c|}
\hline Vital sign & 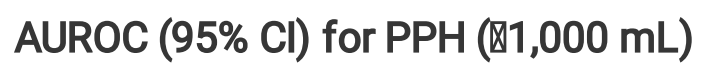 & AUROC $(95 \% \mathrm{Cl})$ for PPH $(\mathbb{1} 1,500 \mathrm{~mL})$ \\
\hline peak SI & $0.646(0.590-0.700)$ & $0.665(0.582-0.748)$ \\
\hline HR of peak SI & $0.540(0.474-0.605)$ & $0.574(0.486-0.662)$ \\
\hline SBP of peak SI & $0.580(0.561-0.605)$ & $0.607(0.561-0.643)$ \\
\hline
\end{tabular}

According to our data, the mean peak SI in surgical interventions was $0.93 \pm 0.19$, the mean peak SI in blood transfusion was $0.98 \pm 0.24$. Age, BMI, delivery mode, fetal macrosomia, placenta accreta, placenta previa, low-lying placenta, HR of peak SI and caesarean-scarred uterus were associated with surgical interventions. Logistic regression showed delivery mode (caesarean delivery) and placenta previa to be independent risk factors for surgical interventions (Table 4).

Table 4

Univariate and logistic regression to identify markers associated with surgical interventions

\begin{tabular}{|llllll|}
\hline Univariate regression & Value & $\mathbf{p}$ & OR & 95\%Cl Lower & 95\% Cl Upper \\
\hline age & 1.753 & 0.020 & & & \\
\hline BMI & 2.961 & 0.000 & & & \\
\hline delivery mode & 173.021 & 0.000 & 18.686 & 10.177 & 34.308 \\
\hline fetal macrosomia & 6.658 & 0.010 & 0.265 & 0.090 & 0.781 \\
\hline placenta accreta & 126.564 & 0.000 & 13.851 & 7.605 & 25.228 \\
\hline placenta previa & 177.654 & 0.000 & 35.363 & 15.161 & 82.485 \\
\hline Cesarean-scarred uterus & 30.418 & 0.000 & 6.985 & 3.132 & 15.577 \\
\hline Low-lying placenta & 12.042 & 0.001 & & & \\
\hline HR of peak SI & 1.921 & 0.000 & & & $95 \% \mathrm{Cl}$ upper \\
\hline Logistic regression & $\mathbf{B}$ & $\mathbf{P}$ & OR & $95 \% \mathrm{Cl}$ lower & 9. \\
\hline delivery mode & 1.967 & 0.000 & 7.150 & 3.555 & 14.381 \\
\hline placenta previa & 2.302 & 0.000 & 9.989 & 3.918 & 25.472 \\
\hline BMI: Body mass index, Sl: shock index, HR: heart rate, Cl: confidence interval, OR: odds ratio \\
\hline
\end{tabular}

$\mathrm{BMI}$, delivery mode, placenta accreta, placenta previa, caesarean-scarred uterus, and peak $\mathrm{SI} \geq 1$ and $\mathrm{HR}$ of peak SI were associated with blood transfusion. Four of these risk factors (BMI, delivery mode, placenta previa, peak $\mathrm{SI} \geq 1$ ) were independent risk factors for blood transfusion (Table 5). 
Table 5

Univariate and logistic regression to identify markers associated with blood transfusion

\begin{tabular}{|c|c|c|c|c|c|}
\hline Univariate regression & Value & p & OR & 95\%Cl Lower & 95\% Cl Upper \\
\hline BMI & 3.709 & 0.000 & & & \\
\hline delivery mode & 80.274 & 0.000 & 11.735 & 5.926 & 23.240 \\
\hline placenta accreta & 63.355 & 0.000 & 9.969 & 4.964 & 20.018 \\
\hline placenta previa & 120.971 & 0.000 & 15.316 & 7.998 & 29.330 \\
\hline Cesarean-scarred uterus & 41.270 & 0.000 & 8.029 & 3.776 & 17.073 \\
\hline Peak $S I \geq 1$ & 12.999 & 0.000 & 2.805 & 1.564 & 5.030 \\
\hline HR of peak SI & 2.158 & 0.000 & & & \\
\hline Logistic regression & B & $\mathbf{p}$ & OR & $95 \% \mathrm{Cl}$ lower & $95 \% \mathrm{Cl}$ upper \\
\hline BMI & -0.172 & 0.011 & 0.842 & 0.737 & 0.962 \\
\hline delivery mode & 1.876 & 0 & 6.529 & 2.588 & 16.473 \\
\hline placenta previa & 1.84 & 0 & 6.297 & 2.701 & 14.681 \\
\hline Peak $S I \geq 1$ & 1.638 & 0 & 5.143 & 2.331 & 11.345 \\
\hline
\end{tabular}

The sensitivity, specificity, positive likelihood ratio and negative likelihood ratio, negative predictive value for $\mathrm{SI} \geq 1$ to predict blood transfusion were 0.39 (95\% Cl:0.28 -0.52), $0.81(95 \% \mathrm{Cl}: 0.76-0.86), 2.10$ and $0.75,82 \%$ respectively.

\section{Discussion}

This retrospective study showed that SI proved superior to vital signs in detecting PPH. Among vital signs often used to estimate postpartum blood loss, including HR, SBP, SI, SI correlated better with blood loss during pregnancy in our patients, as suggested in previous work [16]. SI was less accurate than drapes weighing method in estimating PPH. The average SI was 0.8 when PPH $₫ 500 \mathrm{ml}$ and increased with blood loss after delivery with placenta. Anesthetics may decrease SI during caesarean section. Peak SI had an unexpectedly low correlation with blood loss. Our data showed that the corresponding blood loss was about $1500 \mathrm{ml}$ when SI was 1 . According to the data, the mean peak SI in surgical interventions was about 0.9 , the mean peak SI in blood transfusion was about 1.0, We analysed the relationship between $S I \geq 1$ and surgical intervention and blood transfusion, and found that $S I \geq 1$ was an independent risk factor for blood transfusion, in accordance with the literature [17]. 
Our data showed that the corresponding SI was 0.87 and 0.92 when the blood loss was $500-1000 \mathrm{~mL}$ and $1000-1500 \mathrm{ml}$. Clinically, more than $1000 \mathrm{ml}$ of blood loss is usually required for blood transfusion, which may affect the further rise of SI. According to the literature [14, 18], SI values corresponding to blood loss between pregnant and non-pregnant women at all stages are as follows: When the blood loss ratio of pregnant women is $10 \%-30 \%$, the corresponding SI is 1.0, while the blood loss ratio of non-pregnant women is $15 \%-20 \%$, the corresponding SI is $>1.0-1.5$. When the blood loss ratio of pregnant women is $30 \%-50 \%$, the corresponding $\mathrm{SI}$ is 1.5 , while the blood loss ratio of non-pregnant women is $20 \%-40 \%$, the corresponding SI is 1.5-2.0. When the blood loss ratio of pregnant women is $50 \%-70 \%$, the corresponding $\mathrm{SI}$ is 2.0 , while the blood loss ratio of non-pregnant women is $40 \%-50 \%$, the corresponding $\mathrm{SI}$ is $>2.0$. We can conclude that pregnant women have more blood loss with the same SI because of the physiological changes characteristic of pregnancy including increased cardiac output and circulatory blood volume, decreased systemic vascular resistance which caused hemodilution. For the same amount of blood loss, pregnant women have less hemoglobin decline, thus enabling pregnant women to have stronger compensative capacity $[16,19]$.

Delivery mode, mainly referring to caesarean section, was an independent risk factor for surgical interventions and blood transfusion. As usual, patients choose caesarean section because of complications such as caesarean-scarred uterus, fetal macrosomia, twin birth, placenta implantation, placenta previa, et al, which had a potential risk of bleeding, leading to a higher incidence of surgical interventions and blood transfusion. BMI, delivery mode, peak $S I \geq 1$, and placenta previa were independent risk factors for blood transfusion. The lower the BMI, the easier it is to have blood transfusion. Generally, the lower the BMI, the lower the relative weight, the less the relative blood volume. For the same amount of bleeding, the lower the blood volume, the higher the bleeding proportion, the higher the corresponding SI, the worse the compensative capacity, the more necessary blood transfusion is needed. This view is a little different from the previous report [20,21]. As placenta previa was an independent risk factor for surgical interventions and blood transfusion, we suggest that in the case of patients with placenta previa, clinicians should prepare large amounts of blood products before operation and prepare for the uterine artery embolization or hysterectomy during operation to ensure patients' life security in the event of uncontrolled intraoperative bleeding.

In our study, SI over 1 predicted transfusion with a specificity of 0.81 , negative predictive value $82 \%$ but sensitivity of only 0.39 . A previous study $[22,23]$ showed that SI positively correlated with the volume of blood product transfusion and level of fibrinogen. Takafumi Ushida et al reported the cutoff points of SI for PPH ( $\geq 1,000 \mathrm{ml}$ ) was 0.86 (sensitivity, 53.9\%; specificity, 76.0\%) [13]. These observations suggested that SI correlated with the need for transfusion with high specificity and negative predictive value which could be used in excluding blood transfusion. However, the low sensitivity of SI and low correlation with blood loss limited its ability to estimate PPH and predict blood transfusion. SI should combine with other vital signs (HR, SBP), clinical manifestations (state of consciousness, cold skin, urine volume, thirst, edema), laboratory indicators (blood routine, blood coagulation, thromboelastography), Electrocardiograph(ECG) monitor (oxygen saturation), arterial blood gas analysis (lactate (Lac), hematocrit(HCT), potential of hydrogen(PH), base excess $(\mathrm{BE})$ ), Pressure index (central venous pressure, 
CVP), dynamic index (volume load test) and volume index (general end-diastolic volume(GEDV), Intrathoracic Blood Volume (ITBV)) to judge the severity of PPH[24, 25].

In the study, we chose $\mathrm{Hb} 24$ hours after delivery as the reference standard to avoid the influence of blood concentration, and chose the maximum SI within 24 hours after delivery to reduce the influence of anaesthetic drugs and drugs that raise blood pressure. Our study presents two limitations. First, our work was limited by its retrospective design, with all the potential errors inherent to this type of study. Second, patients were excluded if they had massive haemorrhage $(>5 \mathrm{~L})$, gestational hypertension, hyperthyroidism, hypothyroidism, sinus tachycardia or sinus bradycardia. Thus, our results may not apply to patients with those complications. This study had a large sample size and a complete collection of samples, which ensured the reliability of the conclusion to some extent.

\section{Conclusions}

Peak SI was superior to vital signs to identify PPH. SI $<1$ may indicate that blood transfusion is not needed. SI should combine with other vital signs, clinical manifestations, laboratory indicators, ECG monitor, arterial blood gas analysis et al to identify PPH. The SI proposed here should be prospectively explored in larger cohorts.

\section{List Of Abbreviations}

SI: shock index

SBP: systolic blood pressure,

PPH: postpartum hemorrhage

AUROC: area under the receiver operating characteristic curve

Cl: confidence interval

BMI: body mass index

$\mathrm{Hb}$ : hemoglobin

ECG: Electrocardiograph

Lac: lactate

HCT: hematocrit

$\mathrm{PH}$ : potential of hydrogen,

BE: base excess 
CVP: central venous pressure

GEDV: general end-diastolic volume

ITBV: Intrathoracic Blood Volume

\section{Declarations}

\section{Acknowledgements}

Not applicable.

\section{Authors' contributions}

Liqiong Huang, Xiaoqin Gan and Zheng'ai Xiong wrote the main manuscript text, Dan Luo, Jiajia Zhang and Mengjun Wu prepared figures and tables. All authors reviewed the manuscript.

\section{Funding}

No funding was received for conducting this study.

\section{Availability of data and materials}

The datasets analysed during the current study are not publicly available due to privacy concern but are available from the corresponding author on reasonable request.

\section{Declarations Ethics approval and consent to participate}

This research study was conducted retrospectively from data obtained for clinical purposes. We provided the ethical approval from the Ethics committee of Chengdu Women's and Children's Central Hospital. All methods were carried out in accordance with relevant guidelines and regulations. The requirement for written informed consent was waived from the Ethics committee of Chengdu Women's and Children's Central Hospital because of the retrospective nature of the study.

\section{Consent for publication}

Not applicable.

\section{Competing interests}

The authors declare that they have no competing interests.

\section{Author details}

1: at department of obstetrics and gynecology, Chengdu Women's and Children's Central Hospital, School of Medicine, University of Electronic Science and Technology of China. Chengdu city, Sichuan province, 
China.

2: at department of obstetrics and gynecology, the Second Affiliated Hospital of Chongqing Medical University. Address: No.76 Linjiang Road, Yuzhong district, Chongqing, China. Postal code:400000. Email: 300534@hospital.cqmu.edu.cn.Ph: +8613908359484.

\section{References}

1. Gynecologists ACoOa. ACOG Practice Bulletin: Clinical Management Guidelines for ObstetricianGynecologists Number 76, October 2006: postpartum haemorrhage. Obstet Gynecol. 2006;108(4):1039-47.

2. Bulletins-Obstetrics CoP. Practice Bulletin No. 183: Postpartum Haemorrhage. Obstet Gynecol. 2017;130(4):e168-e86.

3. Collaborators WT. Effect of early tranexamic acid administration on mortality, hysterectomy, and other morbidities in women with post-partum haemorrhage (WOMAN): an international, randomised, double-blind, placebo-controlled trial. Lancet. 2017;389(10084):2105-16.

4. Collaborators GMM. Global, regional, and national levels of maternal mortality, 1990-2015: a systematic analysis for the Global Burden of Disease Study 2015. Lancet. 2016;388(10053):1775812.

5. Say L, Chou D, Gemmill A, Tunçalp Ö, Moller AB, Daniels J, et al. Global causes of maternal death: a WHO systematic analysis. Lancet Glob Health. 2014;2(6):e323-33.

6. Souza JP, Gülmezoglu AM, Vogel J, Carroli G, Lumbiganon P, Qureshi Z, et al. Moving beyond essential interventions for reduction of maternal mortality (the WHO Multicountry Survey on Maternal and Newborn Health): a cross-sectional study. Lancet. 2013;381(9879):1747-55.

7. Sheldon WR, Blum J, Vogel JP, Souza JP, Gülmezoglu AM, Winikoff B, et al. Postpartum haemorrhage management, risks, and maternal outcomes: findings from the World Health Organization Multicountry Survey on Maternal and Newborn Health. BJOG. 2014;121 Suppl 1:5-13.

8. Collaborative CMQCC. California Partnership for Maternal Safety 2016 [cited 2016 Oct 31]. Available from: https://www.cmqcc.org/projects/california-partnership-maternal-safety.

9. Jaramillo S, Barnhart K, Takacs P. Use of the shock index to predict ruptured ectopic pregnancies. Int J Gynaecol Obstet. 2011;112(1):68.

10. Birkhahn RH, Gaeta TJ, Bei R, Bove JJ. Shock index in the first trimester of pregnancy and its relationship to ruptured ectopic pregnancy. Acad Emerg Med. 2002;9(2):115-9.

11. Birkhahn RH, Gaeta TJ, Van Deusen SK, Tloczkowski J. The ability of traditional vital signs and shock index to identify ruptured ectopic pregnancy. Am J Obstet Gynecol. 2003;189(5):1293-6.

12. WHO Guidelines Approved by the Guidelines Review Committee. Geneva: World Health Organization, 2018. 
13. Ushida T, Kotani T, Imai K, Nakano-Kobayashi T, Nakamura N, Moriyama Y, et al. Shock Index and Postpartum Hemorrhage in Vaginal Deliveries: A Multicenter Retrospective Study. Shock. 2021;55(3):332-7.

14. Obstetrics Subgroup CSoO, Gynecology CiMA, Association OSCSoO, Medical GC. [Guideline of prevention and treatment about postpartum haemorrhage (2014)]. Zhonghua Fu Chan Ke Za Zhi. 2014;49(9):641-6.

15. Xie X, Kong B, Duan T. Obstetrics and Gynecology. 9th ed. Beijing (CN): People's medical publishing house; 2018. Chinese.

16. Pacagnella RC, Souza JP, Durocher J, Perel P, Blum J, Winikoff B, et al. A systematic review of the relationship between blood loss and clinical signs. PLoS One. 2013;8(3):e57594.

17. El Ayadi AM, Nathan HL, Seed PT, Butrick EA, Hezelgrave NL, Shennan AH, et al. Vital Sign Prediction of Adverse Maternal Outcomes in Women with Hypovolemic Shock: The Role of Shock Index. PLoS One. 2016;11(2):e0148729.

18. Liu LM, Bai XJ, Li T, Zhou XY, Yang GM, Gao W, et al. Early treatment specifications for traumatic haemorrhagic shock. Journal of Traumatic Surgery. 2012; 19 (12): (881-883, 891).

19. Sanghavi M, Rutherford JD. Cardiovascular physiology of pregnancy. Circulation. 2014;130(12):1003-8.

20. De Jong A, Deras P, Martinez O, Latry P, Jaber S, Capdevila X, et al. Relationship between Obesity and Massive Transfusion Needs in Trauma Patients, and Validation of TASH Score in Obese Population: A Retrospective Study on 910 Trauma Patients. PLoS One. 2016;11(3):e0152109.

21. Maneschi F, Perrone S, Di Lucia A, laniri P. Shock parameters and shock index during severe postpartum haemorrhage and implications for management: a clinical study. J Obstet Gynaecol. 2020;40(1):40-5.

22. Era S, Matsunaga S, Matsumura H, Murayama Y, Takai Y, Seki H. Usefulness of shock indicators for determining the need for blood transfusion after massive obstetric hemorrhage. J Obstet Gynaecol Res. 2015;41(1):39-43.

23. Le Bas A, Chandraharan E, Addei A, Arulkumaran S. Use of the "obstetric shock index" as an adjunct in identifying significant blood loss in patients with massive postpartum hemorrhage. Int J Gynaecol Obstet. 2014;124(3):253-5.

24. Richards JB, Wilcox SR. Diagnosis and management of shock in the emergency department. Emerg Med Pract. 2014;16(3):1-22; quiz -3.

25. Reale SC, Farber MK. Point-of-care coagulation testing for obstetric hemorrhage: time for a theranostic approach? Int J Obstet Anesth. 2019; 38:1-3.

\section{Figures}




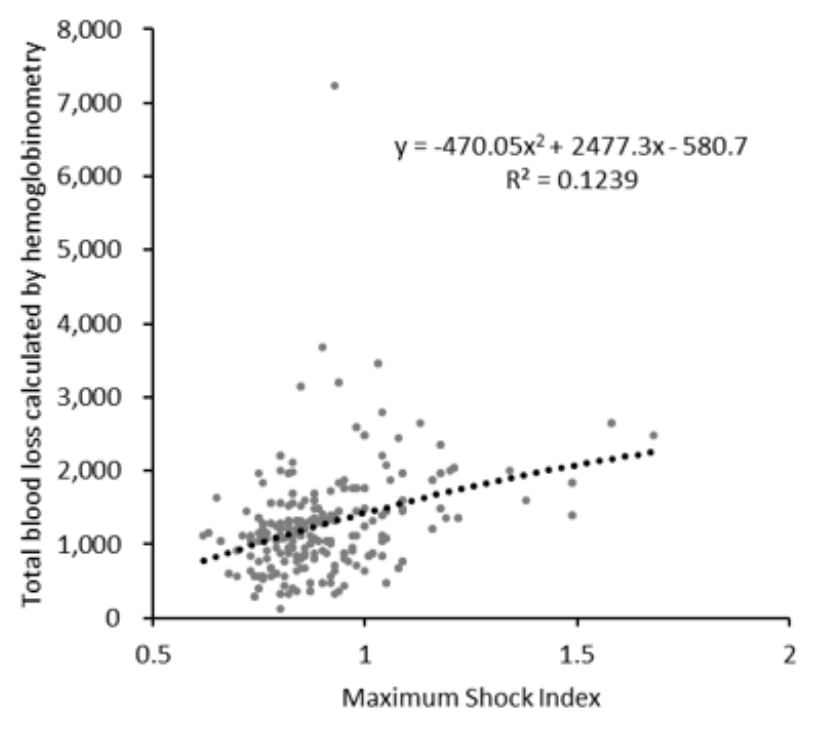

(a)

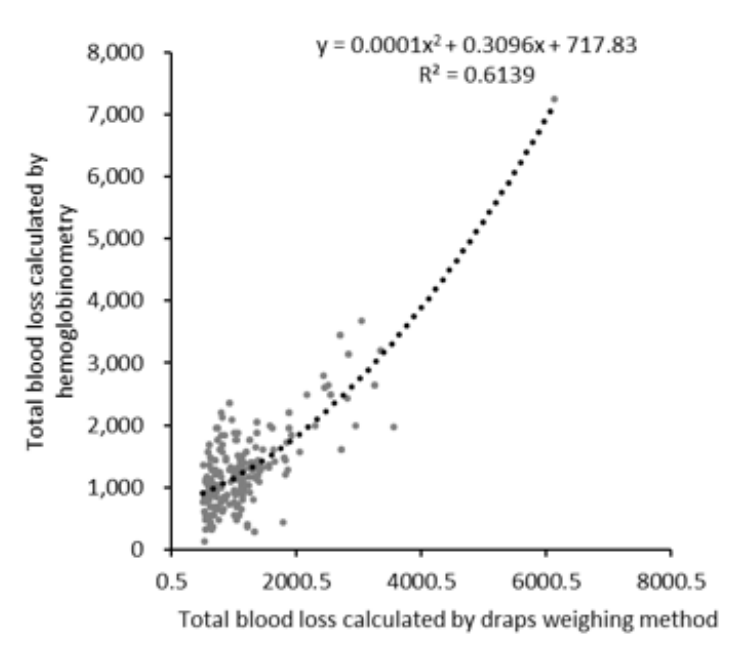

(b)

\section{Figure 1}

a)coefficient of correlation $₫ 0.351$

Figure a a fitted curve with the maximum shock index plotted against total blood loss calculated by hemoglobinometry for the PPH group and control group

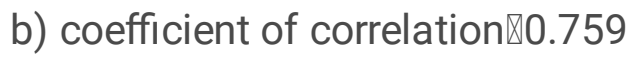

Figure $\mathrm{b}$ a fitted curve with blood loss postpartum $24 \mathrm{~h}$ based on draps weighing method against blood loss postpartum $24 \mathrm{~h}$ with hemoglobinometry 